\title{
Chromosome Polymorphism and Human Pathology: About 27 Cases of Chromosome 9 Inversion in the Beninese Population
}

\author{
Simon Azonbakin 1*, Alfred Ouedraogo², Alexis Ouedraogo², Daniel Sewadouno", \\ Arnaud Agbanlinsou' ${ }^{1}$, Yannick Goussanou${ }^{1}$, Marius Adjagba1, Jules Alao ${ }^{3}$, Anatole Laleye ${ }^{1}$ \\ ${ }^{1}$ Laboratory of Histology-Reproductive Biology, Cytogenetics and Medical Genetics, Human Biology Unit, Faculty of Health \\ Sciences, Abomey-Calavi University, Cotonou, Benin \\ ${ }^{2}$ Laboratory of Histology-Embryology, Cytogenetics and Reproductive Biology, Teaching Hospital of Bogodogo, Ouagadougou, \\ Burkina Faso \\ ${ }^{3}$ Department of Pediatric and Medical Genetic, Faculty of Health Sciences, Abomey-Calavi University, Cotonou, Benin \\ Email: ^azandeg@yahoo.fr
}

How to cite this paper: Azonbakin, S. Ouedraogo, A., Ouedraogo, A., Sewadouno, D., Agbanlinsou, A., Goussanou, Y., Adjagba, M., Alao, J. and Laleye, A. (2021) Chromosome Polymorphism and Human Pathology: About 27 Cases of Chromosome 9 Inversion in the Beninese Population. Open Journal of Genetics, 11, 23-31.

https://doi.org/10.4236/ojgen.2021.113003

Received: February 11, 2021

Accepted: August 3, 2021

Published: August 6, 2021

Copyright $\odot 2021$ by author(s) and Scientific Research Publishing Inc. This work is licensed under the Creative Commons Attribution International License (CC BY 4.0).

http://creativecommons.org/licenses/by/4.0/

\begin{abstract}
The chromosomal polymorphism defined by variations of some chromosomal regions of a person (the constitutive heterochromatin and the short arms of the acrocentric chromosomes (13 to 15 and $21-22)$ ) sometimes highlighted problems with regard to their safety and their pathogenicity. Polymorphisms are usually found in the same family and transmitted in the dominant Mendelian. Chromosome 9 inversion is a frequent phenomenon that some cytogeneticists consider as a variant of normal. Despite its classification as a minor chromosome rearrangement which does not correspond to abnormal phenotypes, many reports have raised conflicting opinions as well, and its complete safety is controversial. 27 cases of inversion of chromosome 9 were identified in our laboratory. The main indications for karyotype of the case of inv (9) were congenital cardiopathy (18.5\%), sex development disorders of (18.5\%), down syndrome (18.5\%), and infertility (14.8\%). This study stood out the observations of many authors who highlighted the involvement of inv (9) in the genesis of several pathologies.
\end{abstract}

\section{Keywords}

Inversion, Chromosome 9, Karyotype, Abnormality, Fertility

\section{Introduction}

Constitutional chromosomal abnormalities are an important cause of miscar- 
riage, infertility, congenital anomalies, and mental retardation in humans. Constitutional chromosomal abnormalities include numeral chromosomal aberrations that cause aneuploidy and structural chromosomal aberrations such as translocations, inversions, deletions, and duplications [1]. The frequency of structural chromosomal abnormalities has been estimated at $0.25 \%$ in live-born infants [2] [3]. Chromosomal polymorphisms of constitutive heterochromatin regions of chromosomes 1, 9, 16, and the Y chromosome were reported. The pericentric inversion of chromosome 9 (inv (9)) is one of the most common structural balanced chromosomal variations and was found in both normal and affected populations [4] [5]. The incidence is approximately $1 \%$ to $3 \%$ in the general population [3] [4]. Most cytogeneticists consider it as a normal variant because of the occurrence of inv (9). Despite its categorization as a minor chromosomal rearrangement, which is not related to abnormal phenotype, some reports described inv (9) in association with subfertility and recurrent abortions, abnormal clinical conditions, as well as other chromosomal abnormalities [6] [7] [8].

In order to study the frequency and the phenotype associated with inv (9), we reported 27 cases, in the Laboratory of Histology-Biology of Reproduction, Cytogenetics and Medical Genetics of Cotonou, Benin.

\section{Methods}

It was a retrospective study including cases of inv (9) at the Cytogenetics Laboratory of Cotonou from January 1, 2014 to June 30, 2020. The data were collected in the laboratory's registers. As they were routine patients, a written approval was not obtained from the ethical committee of Faculty of Health Science of Cotonou.

The study population includes all the patients admitted to laboratory during the study period. The karyotype was performed in a $\mathrm{G}$ band. The culture tubes were incubated for 72 hours at $37^{\circ} \mathrm{C}, \mathrm{CO}_{2} 5 \%$. The culture was stopped at the $70^{\text {th }}$ hour by adding $50 \mu \mathrm{l}$ of colcemide $\left(\mathrm{Sigma}^{\mathrm{R}}\right)$. Hypotonic treatment of the cells with $\mathrm{KCl}(0.075 \mathrm{M})$ followed by fixation in ethanol/glacial acetic acid (3:1 vol; vol). A concentrated suspension of cells was placed on slides and dried, for 25 minutes. The chromosomes were obtained by digestion in a trypsin bath and stained using $2 \%$ Giemsa solution. They were then dried and examined under the microscope using the programmed image analyzer (Cytovision 7.3.1). The metaphases were captured using a microscope and interpreted in accordance with the international system of Human Cytogenetic Nomenclature (ISCN).

\section{Results}

Over 5-year, 1049 karyotypes were performed. Inv (9) was observed in 27 cases $(2.57 \%)$. The inv (9) was predominant in male subjects with a sex ratio of 1.17.The average age of the patients was 12.65 years with extremes from 03 months to 39 years. The majority (46.15\%) of our patients were between 0 and 1 year of age. Table 1 summarizes the clinical and genetypical information about the cases of inv (9). The main indications for karyotype of the case of inv (9) 
were congenital cardiopathy (18.5\%), sex development disorders of (18.5\%), Down Syndrom (18.5\%), and Infertility (14.8\%). The other indication was facial dysmorphy (7.4\%), Suspicion of Klinefelter syndrome (3.7\%), psychomotor delay (3.7\%), polymalformative syndrome (3.7\%), recurrent abortions $(3.7 \%)$ and hypotrophy (7.4\%). Table 1 summarized clinical feature of patient with inv chr9 and genotypic finding.

The type of inversion observed was q11-q22.3. We also observed a case with mosaicism 46, XX (85\%)/46, XX, inv (9), five cases associated with Down's syndrome and one case with duplication of chromosome 9 (46, XY, inv (9), dup (q13 P11). Figures 1-4 show metaphasic finding of some genotypics aspects of inv chr (9).

Table 1. Clinical and genetypical information about the cases of inv chr (9).

\begin{tabular}{|c|c|c|c|c|}
\hline Case & Sex & Age (years) & Clinical aspects & Genotypics forms \\
\hline Case 1 & $\mathrm{~F}$ & 0.25 (3 months) & Congenital Cardiopathy & $46, \mathrm{XX}, \operatorname{inv}(9)$ \\
\hline Case 2 & $\mathrm{~F}$ & 0.33 (4 months) & Developpement sexual disorders (DSD) & $46, X X, \operatorname{inv}(9)$ \\
\hline Case 3 & M & 0.75 (9 months) & Congenital Cardiopathy & $46, X Y$, inv (9) \\
\hline Case 4 & M & 31 & Infertility (severe oligospermia) & $46, X Y$, inv (9) \\
\hline Case 5 & M & 0.75 (9 months) & Developpement sexual disorders (DSD) & $46, X Y$, inv (9) \\
\hline Case 6 & $\mathrm{~F}$ & 35 & Infertility (primary amenorrhea) & $46, \mathrm{XX}, \operatorname{inv}(9)$ \\
\hline Case 7 & M & 0.75 (9 months) & Facial dysmorphia & $46, \mathrm{XY}$, inv (9) \\
\hline Case 8 & $\mathrm{~F}$ & 1 & Congenital Cardiopathy & $46, \mathrm{XX}, \operatorname{inv}(9)$ \\
\hline Case 9 & M & 38 & Developpement sexual disorders (DSD) & $46, X Y, \operatorname{inv}(9)$ \\
\hline Case 10 & M & 15 & Facial dysmorphia & $46, \mathrm{XY}$, inv (9) \\
\hline Case 11 & M & 39 & Suspicion Klinefelter's syndrome & $46, \mathrm{XY}, \operatorname{inv}(9)$ \\
\hline Case 12 & $\mathrm{~F}$ & 0.60 (8 months) & Congenital Cardiopathy & $\begin{array}{c}\text { 46, XX (85\%)/46, XX, } \\
\operatorname{inv}(9)(15 \%)\end{array}$ \\
\hline Case 13 & $\mathrm{~F}$ & 2 & Down syndrome & $47, \mathrm{XX},+21, \operatorname{inv}(9)$ \\
\hline Case 14 & $\mathrm{~F}$ & 14 & Developpement sexual disorders (DSD) & $46, \mathrm{XX}, \operatorname{inv}(9)$ \\
\hline Case 15 & M & 0.75 (9 months) & Down syndrome & $47, \mathrm{XY},+21, \operatorname{inv}(9)$ \\
\hline Case 16 & M & 4 & Congenital Cardiopathy & $46, \mathrm{XY}$, inv (9) \\
\hline Case 17 & M & 0.58 (7months) & Down syndrome & $46, \mathrm{XY},+21, \operatorname{inv}(9)$ \\
\hline Case 18 & M & 10 & Developpement sexual disorders (DSD) & $46, X Y, \operatorname{inv}(9)$ \\
\hline Case 19 & M & 0.75 (9 months) & hypotrophy & $46, \mathrm{XY}, \operatorname{inv}(9)$ \\
\hline Case 20 & M & 1.83 (22 months) & Psychomotor retardation & $46, \mathrm{XY}$, inv (9) \\
\hline Case 21 & M & 1.83 (22months) & Polymalformative syndrome & $47, \mathrm{XY},+13, \operatorname{inv}(9)$ \\
\hline Case 22 & M & 35 & recurrent abortions & $46, \mathrm{XY}$, inv (9) \\
\hline Case 23 & M & 0.25 (3 months) & Down syndrome & $46, \mathrm{XY},+21$, inv (9) \\
\hline Case 24 & $\mathrm{~F}$ & 0.33 (4 months) & Down syndrome & $46, \mathrm{XX},+21$, inv (9) \\
\hline Case 25 & M & 46 & Infertility (oligospermia) & $46, \mathrm{XY}$, inv (9) \\
\hline Case 26 & M & 33 & Infertility (azoospermia hypogonadism) & $46, \mathrm{XY}$, inv (9) \\
\hline Case 27 & M & 0.75 (9 months) & Hypotrophy & 46, XY, inv (9), dup (q13 P11) \\
\hline
\end{tabular}




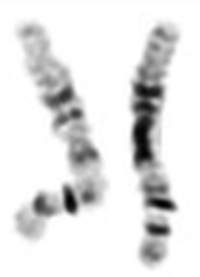

1

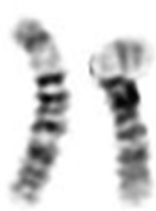

6

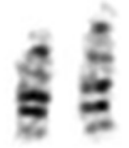

13

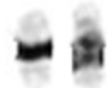

19

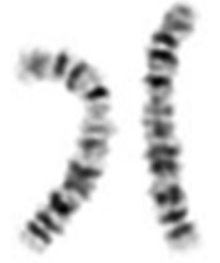

2

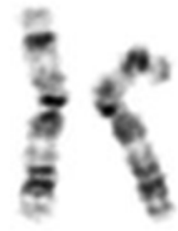

3

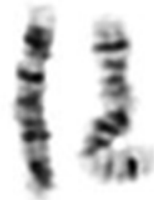

4

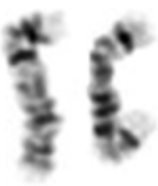

5

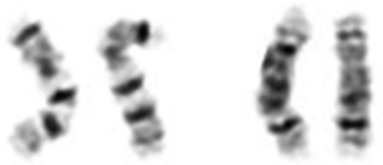

8

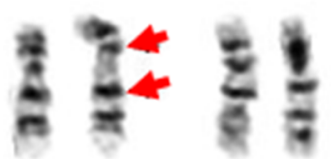

10

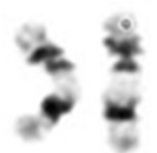

11

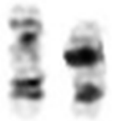

17

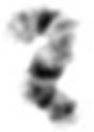

$\mathrm{X}$

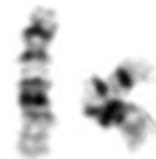

12

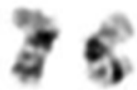

18

Figure 1. Karyotype showing a case of inv chr9 GTG-banded karyotypes of the lymphocytes from patients with pericentric inversion of chromosome 9.

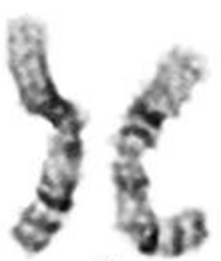

1
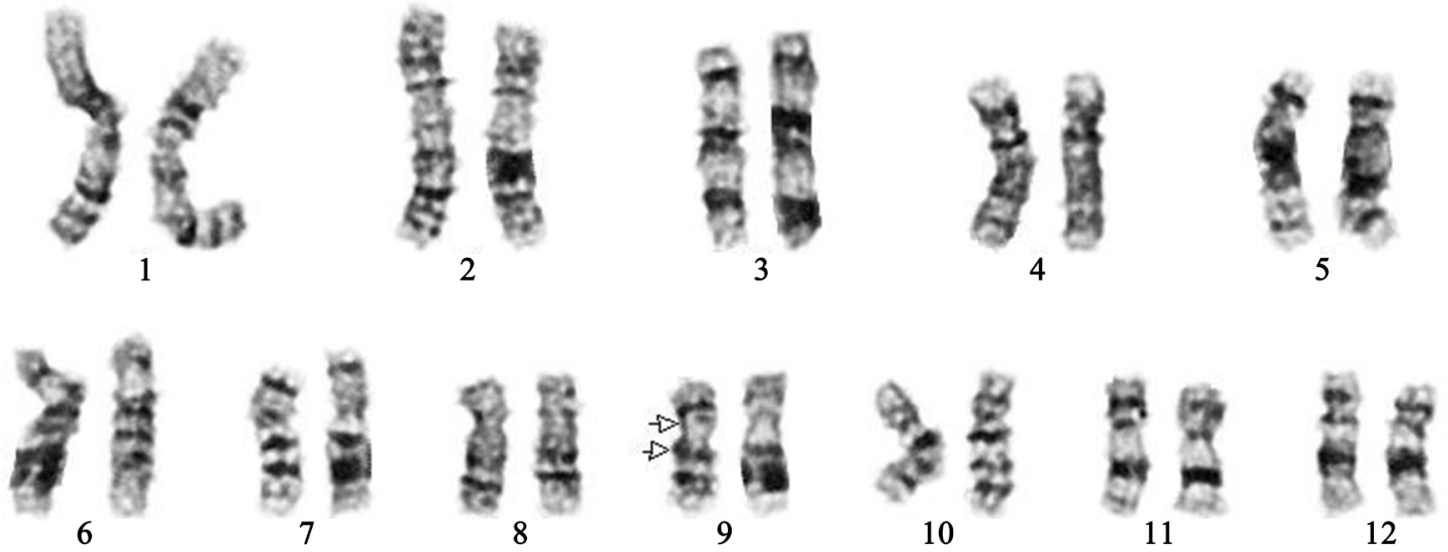

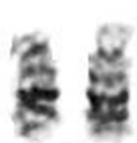

13

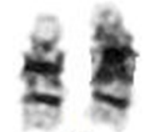

14

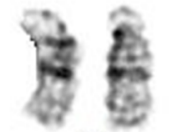

15

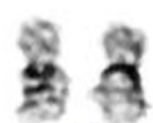

16

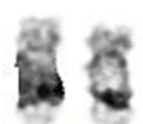

17

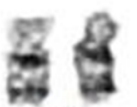

18

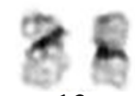

19

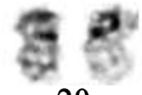

20

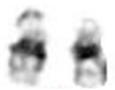

21

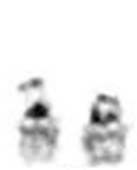

22

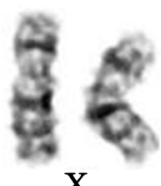

$\mathrm{X}$

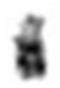

$\mathrm{Y}$

Figure 2. Karyotype showing a case of inv chr9 from a femelle. 46, XX, inv (9). 


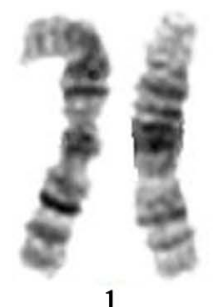

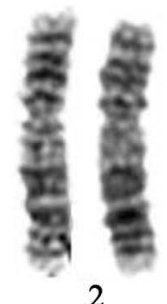

2

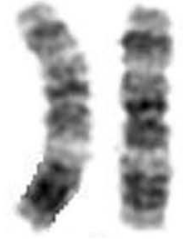

3

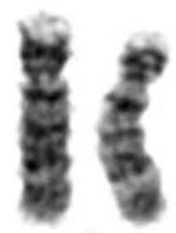

4

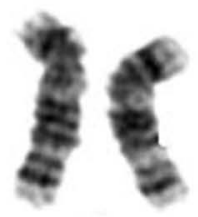

5

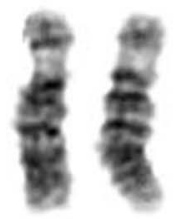

6

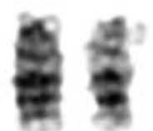

13

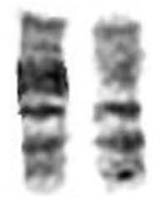

7

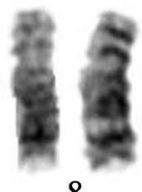

8
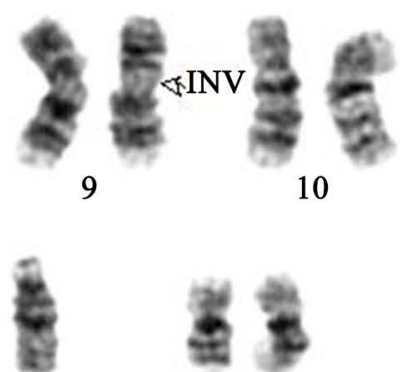

16

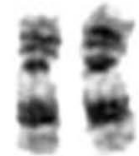

11

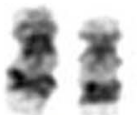

17

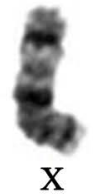

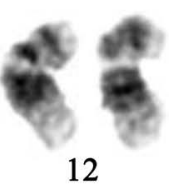

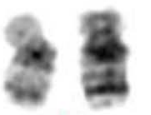

18

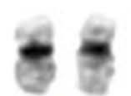

19

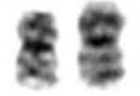

20

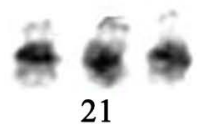

21

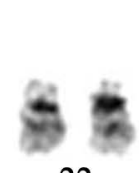

22
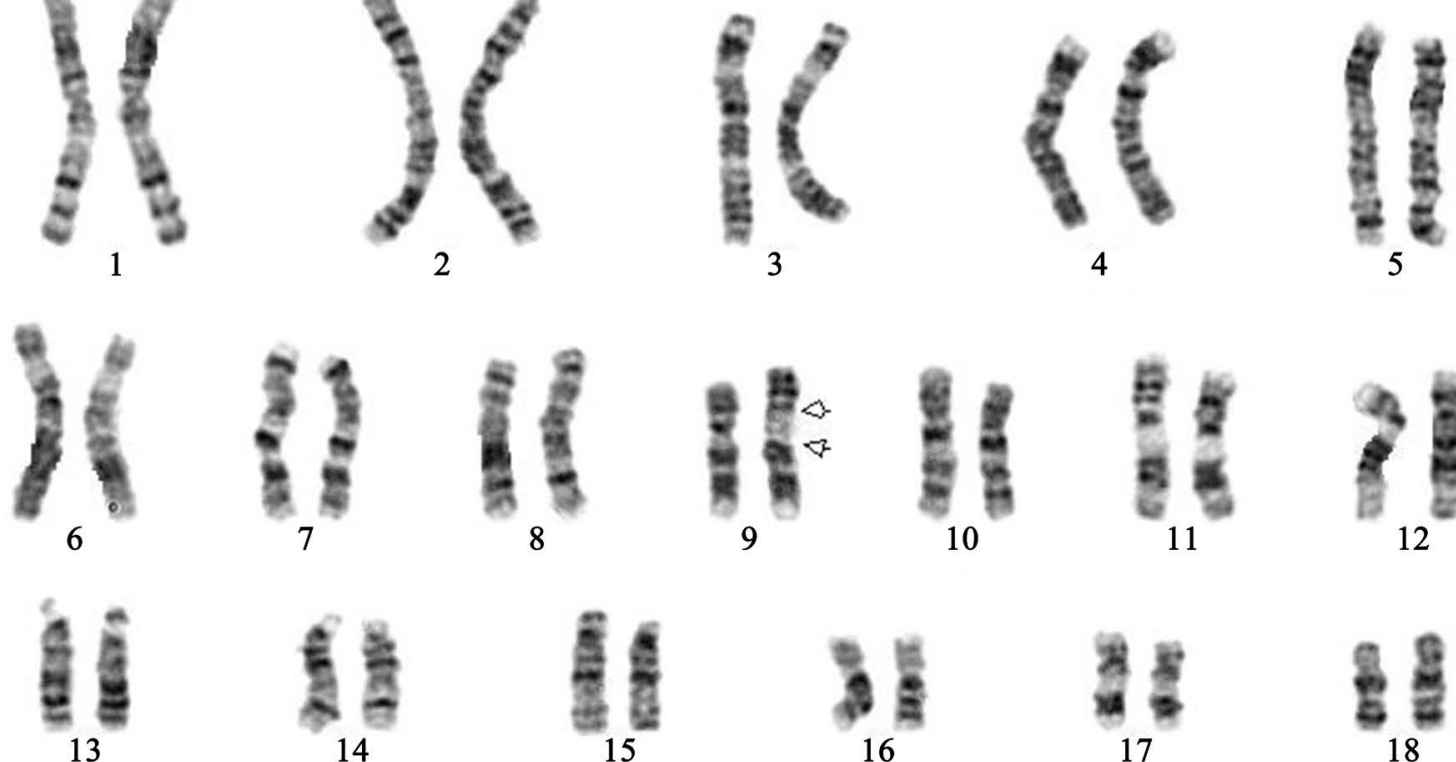

15
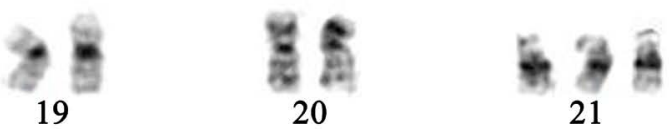

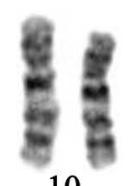

10

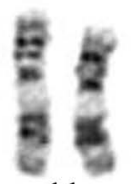

11

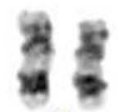

17

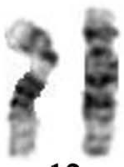

12

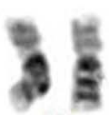

16

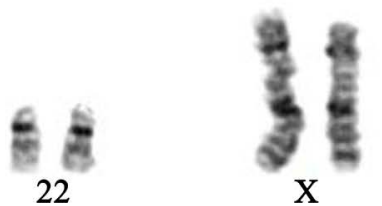

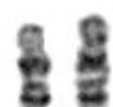

18

Figure 4. Karyotype showing a case of inv chr9 from a femelle with trisomy 21. 47, XX, +21, (inv) 9. 


\section{Discussion}

The inv (9) is a frequent phenomenon, sometimes considered to be a chromosomal polymorphism [7] [9] [10]. Although it does not seem to be correlated with abnormal phenotypes, many controversial reports have been published indicating that it could lead to abnormal clinical conditions. However, when a breakpoint is located in a gene, the inversion affects the phenotype and causes the disease [11].

\subsection{Frequency}

Inv (9), is one of the most common balanced structural chromosomal aberrations and occurs in approximatively $1 \%-1.65 \%$ within a normal population. It's important to notice that the prevalence of the inv chr9 in the general population varies with ethnicity [12]. The pericentric inversion of the Heterochromatic region of chromosome 9 [inv (9)], inv (9) (p11q13), or inv (9) (p12q13), is the most common pericentric inversion found in the human karyotype [11].

In our study, the prevalence of inv Chr9 was 1.64\%. Many other authors have reported the same observation in their studies with an incidence between 1 and $3 \%$ [13]. This incidence may depend on the type of genotipic abnormality associated with inv (9). In Japan, Kiyomi Yamada has reported an incidence of 1.65\% of inv (9) among the whole population and $1.52 \%$ due to Down syndrome patient group. Furthermore, male subjects were predominant in our study as well as reported by some authors [14] [15].

\subsection{Mechanism}

The human chromosome 9 displays the highest degree of structural variability [4]. Pericentric inversion involving the secondary constriction region of chromosome 9 is considered to be a normal variant. A recent study described four unique types of pericentric inversions involving the $9 \mathrm{qh}$ region and suggested that the mechanism leading to appearance of this phenomenon involves break and reunion at the proposed breakpoints [10] [11]. Study of the heterochromatin organization in the pericentromeric region has revealed homology between 9p11-12 and 9q13-21.1. Such homologous sequences could be involved in the mechanism that generates the inversion [10] [11]. In our study, the most common variant is $9 \mathrm{p} 11.1-\mathrm{q} 13$.

\subsection{Clinical Feature}

Chr 9 pericentric inversions are very rare phenomena. In our series, 27 cases, the most common clinical sign were: heart disease, abnormalities in sexual development and infertility. In Korea, Seon-Yong Jeong et al. reported 8 patients with inv (9) presenting various congenital abnormalities, in particular: polydactyly, giant Meckel's diverticulum, poor rotation of the small intestine, cardiomyopathy, pulmonary stenosis [12] [15].

Here, we summarized the literature reviews of some clinical feature on inv (9) 
[16].

\section{Inv (9) and heart disease}

We described 5 cases in our series. Few cases of this association were reported. The gène CFA9 on chromosome 9 is a succeptibility gène involved in the congenital heart defect [12].

\section{Inv (9) and Infertility}

Inv (9) is considered to be a predisposing factor for infertility. Five cases were observed in our study (Oligospermia, azoospermia and primary amenorrhea). Literature has raised divergent views regarding its correlation with hypofertility, recurrent abortions, spermatogenesis disorders and/or unbalanced offspring [9] [17] [18]. Moreover, inv (9), like the other chromosomal polymorphisms, remains an important risk factor of failure in Assistance Reproductive Technology. Many cases of miscarriages were reported to be associated with inv (9) [6] [7]. However, no statistical analyses were performed in these studies.

\section{Inv (9) and Disorders of Sex Development}

Five cases of sex development disturbances were observed in our study. Cases of micropenis and hypospadias associated with inv (9) have been reported [19] [20]. The phenotype can be explained by a disruption in the matching of homologous chromosomes during meiosis and or by the existence of genes of interest at breakpoints. Variants of the SRD5A2 gene are thought to be associated with the occurrence of abnormal sexual development [21].

\section{Inv 9 and Malignant Hematological Disease}

The link between inv (9) and leukemia were frequently reported. Indeed, in a series of 3809 cases of patients with malignant hematological disease, Sang Guk Lee has recorded 586 malignant pathologies and 55 chromosome 9 reversals [22]. This allowed them to conclude that chr9 inv are isolated anomalies that have no connection with malignant hemopathies. No case of malignant was found in our study.

\section{Inv (9) and psychiatic disorders}

Though some authors in literature have mentioned association of inv (9) and psychiatric disorders [8]; none case was recorded in our study

\section{Inv chr9 and prenatal pathology}

Inv (9) is considered as a polymorphic variation and is one of the most common forms of autosomal inversion diagnosed prenatally in amniocytes. Yet its clinical significance remains uncertain. Most publications suggest that this finding is insignificant. However, some articles report on abnormal ultrasonic findings in association, such as hydramnios, anhydramnios, hydroureter, hydronephrosis, encephalocele, and prune belly syndromes [23].

\section{Conclusion}

This study reinforced the observations of several authors who underline the involvement of chromosome 9 inversion in occurring of various pathologies. Molecular cytogenetic examinations such as comparative genomic hybridization 
may prove essential to establish the relationship between the genetic abnormalities of this condition and the consequences on the phenotype of the subject.

\section{Conflicts of Interest}

The authors declare no conflicts of interest regarding the publication of this paper.

\section{References}

[1] Gardner, R.J.M. and Sutherland, G.R. (2004) Chromosome Abnormalities and Genetic Counseling. 3rd Edition, University Press, Oxford, 142-162, 233-246.

[2] Goud, M.T., Al-Harassi, S.M., Al-Khalili, S.A., Al-Salmani, K.K., Al-Busaidy, S.M. and Rajab, A. (2005) Incidence of Chromosome Abnormalities in the Sultanate of Oman. Saudi Medical Journal, 26, 1951-1957.

[3] Duarte, A.C., Cunha, E., Roth, J.M., Ferreira, F.L., Garcias, G.L. and Martino-Roth, M.G. (2004) Cytogenetics of Genetic Counseling Patients in Pelotas, Rio Grande do Sul, Brazil. Genetics and Molecular Research, 3, 303-308.

[4] Ait-Allah, A.S., Ming, P.M.L., Salem, H.T., et al. (1997) The Clinical Importance of Pericentric Inversion of Chromosome 9 in Prenatal Diagnosis. Journal of MaternalFetal Investigation, 7, 126-128.

[5] Teo, S.H., Tan, M., Knight, L., Yeo, S.H. and Ng, I. (1995) Pericentric Inversion 9-Incidence and Clinical Significance. ANNALS Academy of Medicine Singapore, 24, 302-304.

[6] Daya, S. (2006) Issues in the Etiology of Recurrent Spontaneous Abortion. Current Opinion in Obstetrics and Gynecology, 6, 153-159. https://doi.org/10.1097/00001703-199404000-00008

[7] Kumar, M., Thatai, A. and Chapadgaonkar, S.S. (2012) Homozygosity and Heterozygosity of the Pericentric Inversion of Chromosome 9 and Its Clinical Impact. Journal of Clinical and Diagnostic Research, 6, 816-820.

[8] Miyaoka, T., Seno, H., Itoga, M., et al. (1999) A Case of Small Cerebral Cyst and Pericentric Inversion of Chromosome 9 That Developed Schizophrenia-Like Psychosis. Psychiatry and Clinical Neurosciences, 53, 599-602. https://doi.org/10.1046/j.1440-1819.1999.00612.x

[9] Mozdarani, H., Meybodi, A.M. and Karimi, H. (2007) Impact of Pericentric Inversion of Chromosome 9 [inv(9) (p11q12)] on Infertility. Indian Journal of Human Genetics, 13, 26-29. https://doi.org/10.4103/0971-6866.32031

[10] Hsu, L.Y., Benn, P.A., Tannenbaum, H.L., Perlis, T.E. and Carlson, A.D. (1987) Chromosomal Polymorphisms of 1, 9, 16, and Y in 4 Major Ethnic Groups: A Large Prenatal Study. American Journal of Medical Genetics, 26, 95-101. https://doi.org/10.1002/ajmg.1320260116

[11] Kaiser, P. (1984) Pericentric Inversions. Problems and Significance for Clinical Genetics. Human Genetics, 68, 1-47. https://doi.org/10.1007/BF00293869

[12] Demirhan, O., Pazarbasi, A., Suleymanova-Karahan, D. and Tanriverdi, N. (2008) Correlation of Clinical Phenotype with a Pericentric Inversion of Chromosome 9 and Genetic Counseling. Saudi Medical Journal, 29, 946-951.

[13] Yamada, K. (1992) Population Studies of inv(9) Chromosomes in 4300 Japanese: Incidence, Sex Difference and Clinical Significance. The Japanese Journal of Human Genetics, 37, 293-301. https://doi.org/10.1007/BF01883320 
[14] Šípek, A., Panczak, A., Mi halová, R., Hrčková, L., Suttrová, E., Sobotka, V., et al. (2015) Pericentric Inversion of Human Chromosome 9 Epidemiology Study in Czech Males and Females. Folia Biologica (Praha), 61, 140-146.

[15] Jeong, S.-Y., Kim, B.-Y. and Yu, J.E. (2010) De Novo Pericentric Inversion of Chromosome 9 in Congenital Anomaly. Yonsei Medical Journal, 51, 775-780.

https://doi.org/10.3129/i09-119

[16] Andelfinger, G., Wright, K.N., Lee, H.S., Siemens, L.M. and Benson, D.W. (2003) Canine Tricuspid Valve Malformation, a Model of Human Ebstein Anomaly, Maps to Dog Chromosome 9. Journal of Medical Genetics, 40, 320-324. https://doi.org/10.1136/jmg.40.5.320

[17] Mustaqahamed, S., Balachandar, V., Mohanadevi, S., et al. (2011) Identification of Cytogenetic Alterations in Infertile Couples Experiencing Repeated Spontaneous Abortions-Using Giemsa Trypsin Giemsa Banding (GTG). Scientific Research and Essays, 6, 182-186.

[18] Liang, S.S., Yang, J.Z., Wu, H.X., Teng, X.M. and Duan, T. (2019) Effects of Chromosome 9 Inversion on IVF/ICSI: A 7-Year Retrospective Cohort Study. Molecular Genetics \& Genomic Medicine, 7, e856. https://doi.org/10.1002/mgg3.856

[19] Sotoudeh, A., Rostami, P., Nakhaeimoghadam, M., Mohsenipour, R. and Rezaei, N. (2017) Pericentric Inversion of Chromosome 9 in an Infant with Ambiguous Genitalia. Acta Medica Iranica, 55, 655-657.

[20] Hajhouji, S., Hakkou, K. and Gaouzi, A. (2014) Micropenis sur inversion pericentrique du chromosome 9: Quel lien? Annales d Endocrinologie, 75, 313.

https://doi.org/10.1097/00001703-199404000-00008

[21] Labied, A., Sellay, S., Elmokhtari, M. and Gaouzi, A. (2016) Association dysgénésie gonadique et une inversion péricentrique du chromosome 9: Y a-t-il un lien? Annales d' endocrinologie, 77, 453. https://doi.org/10.1016/j.ando.2016.07.592

[22] Lee, S.-G., Park, T.S., Lim, G., Lee, K.-A., Song, J. and Choi, J.R. (2010) Constitutional Pericentric Inversion 9 and Hematological Disorders: A Korean Tertiary Institution's Experience over Eight Years. Annals of Clinical \& Laboratory Science, 40, 273-277.

[23] Parmar, R.C. and Sira, P. (2003) Prenatal Diagnosis of Partial Trisomy 21 Associated with Maternal Balanced Translocation 46,XX,der (21)t(21q;22q) with Pericentric Inversion of Chromosome 9. Journal of Postgraduate Medicine, 49, 154-156. 